\title{
Questes
}

vestes Revue pluridisciplinaire d'études médiévales

12 | 2007

La faim et l'appétit

\section{La faim et l'appétit : introduction}

\section{Anne-Laure Lallouette}

\section{(2) OpenEdition}

\section{Journals}

Édition électronique

URL : http://journals.openedition.org/questes/2702

DOI : 10.4000/questes. 2702

ISSN : 2109-9472

\section{Éditeur}

Les Amis de Questes

\section{Édition imprimée}

Date de publication : 15 juin 2007

Pagination : 5-10

ISSN : 2102-7188

\section{Référence électronique}

Anne-Laure Lallouette, «La faim et l'appétit : introduction », Questes [En ligne], 12 | 2007, mis en ligne le 15 janvier 2014, consulté le 23 septembre 2020. URL : http://journals.openedition.org/questes/2702 ; DOI : https://doi.org/10.4000/questes.2702 


\section{Introduction}

\section{Anne-Laure LALLOUETTE}

Au Moyen Âge, la faim et l'appétit sont deux des trois types de rapports qu'un même individu peut entretenir avec la nourriture, le troisième, présent de manière implicite, est la gourmandise, qui doit être comprise comme la forme outrée des deux premiers. La faim peut être considérée comme une manifestation physiologique commune à tous les êtres vivants, qui les pousse à consommer les aliments nécessaires à leur survie. Elle peut devenir particulièrement cruelle quand aucune nourriture n'est disponible pour la satisfaire. L'appétit, quant à lui, est une pulsion plus complexe vers la nourriture qui implique une discrimination entre les aliments, qui ne provoquent pas de désir uniforme chez ceux à qui ils ont présentés. Un même plat peut susciter attrait ou dégoût en fonction des habitudes alimentaires de l'environnement culturel de chacun. La gourmandise, enfin, correspond à une exagération de ces penchants, elle consiste en une consommation de nourriture qui excède les besoins de l'organisme. Assimilée à un gavage, elle est regardée comme une forme de déchéance de l'être humain qui commet un péché en profitant trop intensément des plaisirs terrestres.

Ces jouissances temporelles peuvent être de plusieurs sortes, comme le laisse entendre la polysémie du terme appétit, qui peut être l'attirance pour une chair alimentaire ou sexuelle, ou bien un appétit plus chaste de savoir. Ainsi, l'appétit peut conduire le fidèle sur le chemin de deux péchés distincts : la gourmandise et la luxure. L'alimentation et la sexualité sont fréquemment assimilées chez les théologiens comme autant d'occasions où les sens échauffés peuvent précipiter l'homme dans le péché. Il existe d'ailleurs une croyance très 
forte en l'efficacité des vertus aphrodisiaques de certains aliments. La forme phallique de quelques légumes ou le caractère considéré comme particulièrement chaud de différents épices sont des éléments déterminants dans les propriétés qui leur sont prêtées.

Pour terrible qu'elle soit, la gourmandise n'est cependant regardée ni comme le premier des péchés ni comme le plus grave par les théologiens. Ceuxci considèrent que c'est sa superbe, son désir orgueilleux d'accéder à la connaissance, qui ont conduit Adam à la faute ; et que la gourmandise, le désir de connaître la saveur du fruit défendu, n'est qu'un « complément » qui aggrave le péché initial ${ }^{1}$. Les péchés liés à la consommation de nourriture font l'objet d'une clémence accrue de la part des penseurs médiévaux à partir du XIII ${ }^{\mathrm{e}}$ siècle, conscients du caractère vital de l'alimentation les maîtres universitaires, à l'instar de saint Thomas d'Aquin, acceptent de considérer le fait de se nourrir comme une nécessité2.

La faim est une ennemie terrible pour les hommes tout au long du Moyen Âge, et les famines un problème endémique. Ces dernières sont régulièrement évoquées dans les chroniques du haut Moyen Âge, moins fréquentes ensuite, au cours des beaux $\mathrm{XII}^{\mathrm{e}}$ et $\mathrm{XIII}^{\mathrm{e}}$ siècles, elles réapparaissent à la fin du $\mathrm{XIII}^{\mathrm{e}}$ siècle. La grande famine de 1315 est souvent considérée comme un des premiers signes des difficultés du XIV ${ }^{\mathrm{e}}$ siècle. Ces aléas frumentaires sont liés à une baisse de la productivité qui peut être imputée au morcellement des territoires agricoles et à la lourdeur des prélèvements fiscaux. En ville, la faim peut s'avérer moins cruelle grâce aux systèmes d'annone ponctuellement mis en place par les municipalités, aggravant ainsi leur endettement. La forte diminution de la population durant les deux derniers siècles ne soulage pas les estomacs, puisque

${ }^{1}$ Cf. Carla CASAGRANDE et Silvana Vecchio, Histoire des péchés capitaux au Moyen Âge, Paris, Aubier, 2000, chapitre : La gourmandise.

2 Tiziana SuAREZ-NANI, " Du goût et de la gourmandise selon Thomas d'Aquin », Micrologus : Natura, scienze e società medievali 10 (2002), p. 313-334. 
la production est toujours désorganisée par les guerres et les désordres climatiques.

Au Moyen Âge, la faim est une réalité tangible, et Marie-Thérèse Lorcin, dans son article « Manger et boire dans les fabliaux : rites sociaux et hiérarchie des plaisirs $»^{3}$, rappelle que pour les plus humbles la nourriture constitue un des problèmes centraux de la vie quotidienne, ce qui apparaît dans certains fabliaux. En effet, si ces derniers n'évoquent jamais explicitement la famine, « cependant montent sur scène des adolescents que le dénuement pousse à voler des vivres ${ }^{4}{ } »$ et apparaissent çà et là quelques personnages réveillés dans leur sommeil par la faim. D'autres documents, contemporains de ces contes à rire, viennent souligner les souffrances liées au manque de nourriture, ainsi la Vita secunda de saint François d'Assise fait mention d'une famine si épouvantable, au début du $\mathrm{XIII}^{\mathrm{e}}$ siècle dans la région d'Assise, que les habitants du contado se faisaient du pain avec des écorces d'arbres et mangeaient des cadavres d'enfants ${ }^{5}$.

Caroline Bynum souligne que le contexte de crises de subsistance induit tout au long du Moyen Âge, et particulièrement à partir de la fin du XIV siècle, un accroissement de la place et du rôle de l'alimentation chez les saintes, et, de manière plus générale, de l'intérêt de l'Église en général ${ }^{6}$.

Très tôt, l'Église a veillé à encadrer strictement les pratiques alimentaires. Ce souci de codification se retrouve dans les règles monastiques qui indiquent très précisément la quantité de nourriture et de boisson requise ainsi que les horaires des repas. Les plus douces d'entre elles accordent à l'abbé la possibilité de dispenser des rations supplémentaires. Ces compléments ne dépendent pas seulement des besoins physiologiques, mais prennent en compte les activités

\footnotetext{
${ }^{3}$ Marie-Thérèse LORCIN, « Manger et boire dans les fabliaux : rites sociaux et hiérarchie des plaisirs », dans Manger et boire au Moyen Âge, Actes du colloque de la Faculté des Lettres de Nice, 15-17 octobre 1982, Paris, Les Belles Lettres, 1984, t. 1, p. 227-237.

${ }^{4}$ Ibid., p. 228.

${ }^{5}$ Vita secunda, Saint François d'Assise, sa vie, ses écrits, trad. Damien Vorreux, Paris, Éd. franciscaines, 1967, livre II, chap XXIII, p. 210.

${ }^{6}$ Caroline Bynum, Jeûnes et festins sacrés. Les femmes et la nourriture dans la spiritualité médiévale, Paris, Éd. du Cerf, 1994.
} 
quotidiennes des moines. Chez saint Benoît, par exemple, une portion additionnelle est accordée en cas de surcroît de travail, surtout s'il s'agit de travaux des champs, ou encore si un moine éprouve une très grande fatigue. L'adoption du travail agricole par les moines, rendue nécessaire par le vœu de pauvreté, implique une mitigation de la sévérité du jeûne, qui se retrouve également pour les grandes fêtes annuelles ${ }^{7}$. Le jeûne n'en reste pas moins un élément fondamental de la vie monastique et de la vie chrétienne en général. Il implique d'accoutumer son corps à la faim, vécue comme une forme de renoncement au monde.

La maîtrise de ses appétits prend parfois une forme extrême chez certaines saintes mystiques, s'apparentant alors à l'anorexie. Rudolph Bell a mis en évidence les similitudes très fortes qui existent entre les pratiques ascétiques particulièrement exigeantes de ces femmes et la description clinique contemporaine de l'anorexie mentale ${ }^{8}$. Le souci de contrôler étroitement ses propres désirs et l'utilisation de l'abstinence alimentaire comme moyen de se libérer de sa famille et d'une société patriarcales sont les plus frappantes. Certaines de ces femmes refusent parfois toute autre forme de nourriture que l'hostie qu'elles reçoivent lors de leur communion quotidienne. Cette attitude provoque la désapprobation de leurs confesseurs, qui ne parviennent pourtant pas à l'éradiquer totalement, dans la mesure où « le renoncement presque total et délibéré à toute nourriture et à toute boisson [est perçu] par les fidèles du Moyen Âge comme la forme d'ascèse la plus authentique et la plus littérale, requérant ce courage et cette folie sacrée qui étaient les marques de la sainteté. ${ }^{9}$ Les plaisirs liés à la sexualité ou à la possession d'argent sont plus rares, il est donc plus facile d'y renoncer qu'à la nourriture.

\footnotetext{
${ }^{7}$ Antoine de VoGÜÉ, « Travail et alimentation dans les règles de saint Benoît et du maître », in Revue bénédictine, 74, 1964, p. 242-251.

${ }^{8}$ Rudolph M. BELL, L'anorexie sainte. Jeûne et mysticisme du Moyen Âge à nos jours, Paris, P.U.F., 1994.

${ }^{9}$ Caroline Bynum, Jeûnes et festins sacrés, op. cit., p. 18.
} 
Il existe cependant des formes d'appétit valorisées par l'Église. Parmi celles-ci, le désir de communier est un élément fondamental de l'ordinaire des fidèles. La transsubstantiation, qui fait de l'hostie la chair du Christ au cours de l'office, justifie l'appétit que chacun ressent au moment de la communion. Catherine de Sienne rappelle dans ses textes que manger le Christ, c'est devenir le Christ $^{10}$. Persiste néanmoins la condamnation par les prédicateurs de ces femmes qui réclament sans cesse le corps du Sauveur, faisant dans le domaine de l'eucharistie preuve d'un trop grand appétit. Là encore, la modération doit dominer. L'appétit du savoir, enfin, trouve toute sa légitimité aux yeux des hommes d'Église. Dans la lettre que Loup de Ferrières envoie à Eginhard en 829, le jeune moine se plaint d'avoir dû faire face, au cours de sa jeunesse, à une pénurie de maîtres qui l'a empêché de «satisfaire [son] avidité » de connaissance $^{11}$. Mis au service de Dieu, le goût de la science est un des rares qu'il ne soit pas nécessaire de modérer.

La société laïque, quant à elle, fait progressivement preuve de plus de relâchement à l'égard des interdits ecclésiastiques et développe les prémisses d'une gastronomie. Riche et variée, la cuisine médiévale repose sur une forte stimulation de l'appétit grâce à la richesse de ses goûts. La multiplicité des saveurs est obtenue grâce à l'utilisation des épices, dont la gamme reste encore restreinte et dominée par les poivres, et surtout par le recours à de nombreuses herbes ${ }^{12}$. Le raffinement des repas médiévaux repose enfin sur une codification de l'attitude des convives à table, à l'instar de ces textes appelés « contenances de table» qui détaillent les postures et les gestes les plus adaptés à la commensalité ${ }^{13}$.

\footnotetext{
${ }^{10}$ Caroline ByNuM, Id, p. 342.

${ }^{11}$ Correspondance de Loup de Ferrières, Léon Levillain (éd. et trad.), 2 vol., 1964, 1, p. 5.

${ }^{12}$ Michel BALARD, "Épices et condiments dans quelques livres de cuisine allemands (XIV ${ }^{\mathrm{e}}$ $\mathrm{XV}^{\mathrm{e}}$ siècles », dans Carole LAMBERT (éd), Du manuscrit à la table. Essais sur la cuisine au Moyen Âge et répertoire des manuscrits médiévaux contenant des recettes culinaires, Paris, Champion, 1992, p. 193-205.

${ }^{13}$ Stefan GLIXELLI, « Les contenances de la table », Romania, XLVII (1921), p. 1-40.
} 
Face à une telle diversité de point de vue, il convient de se demander comment les hommes du Moyen Âge parlent de leur attrait pour la nourriture, de leur désir sexuel et de leur soif de savoir. Par ailleurs, l'inadéquation de la société avec les principes ecclésiastiques entraîne un fléchissement du point de vue de l'Église, surtout dans le cadre de la réflexion scolastique : faut-il y voir la victoire du ventre? Telles sont les questions auxquelles les contributions qui suivent s'attacheront à répondre. 